\title{
Do Small and Medium-sized IT Firms Form Service Partnerships with Non-Local IT Firms? An Assessment of Facilitators
}

by Melike Findikoglu and Mary Beth Watson-Manheim

For small- and medium-sized IT firms, the service partnerships formed with other IT firms are strategic instruments to overcome their resource constraints, increase efficiency and offer complementary services to their customers. Although these firms have a tendency to form local partnerships due to ease of trust building, few of them are engaged in non-local partnerships. This research aims to explore the facilitators of this divergent firm behavior. The findings suggest that a firm's alliance capabilities and organizational proximities between distant partners can substitute the lack of geographical proximity and enable IT SMEs' engagement in non-local service partnerships. More importantly, the type of IT service rendered through the partnership acts as a moderator and determines the extent of the organizational capabilities and proximities.

Melike Findikoglu is a post-doc research fellow at Technion - Israel Institute of Technology.

Mary Beth Watson Manheim is Associate Professor in the Department of Information and Decision Sciences and the Department of Communication in University of Illinois at Chicago. 


\section{Introduction}

The emergence of a knowledge-based economy in the late 1990s led to a shift away from mass manufacturing towards tailored production and knowledge-intensive services; from rigid structures and markets towards flexible accumulation and increased interactions among markets and firms (Contractor, and Lorange 2002; Scott 2006). This transition has also affected the information technology (IT) industry. Rapidly changing technological trends intensified the competition among technology firms and the ability to fulfill complex and innovative technology requirements of the customers became increasingly important. Moreover, technology-based industries have experienced the challenges of globalization and dispersed value chains that cross national boundaries as various business activities (e.g., conceptualization, design, development, and marketing) are performed in different countries (Nambisan 2002).

Current IT products are highly interdependent as a result of complex requirements on the demand side and advanced technologies on the supply side. The products are usually bundled together as systems; few are offered on a stand-alone basis (de Laigue 2004). Mobile security is a relevant example of the phenomenon. Due to technological complexity, the scope of security is not limited to malware implementation but embraces multiple technologies in device management and protection. Thus, mobile security requires specialization in multiple technological components (Casey, 2011). Ultimately, the IT service is a combination of process outputs of multiple technology firms (Dudek, Uebernickel, and Brenner 2009). ).

The characteristics of IT services set a natural demand for partnerships among service providers. Especially for the small- and medium-sized information technology firms (IT SMEs), providing a broader array of resources than they could possibly accumulate internally (Ahuja 2000; Baum, Calabrese, and Silverman 2000); thus, service partnerships are strategic mechanisms to overcome the SMEs' resource constraints (Das, and He 2006; Hannah, and Walsh 2008). Despite its 
importance, this phenomenon is understudied. Previous research on technology-based partnerships focuses mostly on innovation, new product or technology development, and technology exchange (Cantwell, and Colombo, 2007; Hagedoorn, Letterie, and Palm 2007), excluding the cooperation for service provision. The partnerships in the first group aim to reduce technological uncertainty, increase innovative capacity, decrease innovation time-span and enhance market access (Hagedoorn, 1993; Hagedoorn et al., 2007) whereas the latter are motivated by efficiency gains and future business opportunities. In addition to the motivation, we posit that the coordination requirements for these two types of partnerships are dissimilar due to task characteristics of each. These differences call for explicit analysis of the IT service partnerships.

In terms of geographical scope, the IT firms are not limited to their localities; both globalization effects and the availability of advanced information technologies foster the growth of globally organized work, including "non-local partnerships," i.e. the cooperation with distant (domestic or international) partners. This phenomenon is especially salient to service industries, including the IT industry, due to the characteristics of the services. The main inputs for services (such as intellectual property, technical skills, technical and managerial systems) move more quickly and are less costly over distance, implying that the services are less bounded by location (Stuart, and Sorenson 2003). Hence, IT services are can be disaggregated into their components via methodologies such as codification, standardization, and modularization (Mithas, and Whitaker 2007); some of these components may be rendered remotely.

Previous research associates a firm's tendency to form non-local partnerships with firm size; smaller firms are more likely to operate within their localities and cooperate with local partners (Torre, and Rallet 2005) due to fact that the proximity enables trust building (Petruzzelli, Albino, and Carbonara 2007; Belso-Martinez 2010), and reduces search, communication and transaction costs (McCann 1995). At the same time, the internationalization literature provides empirical evidence on the SMEs' international activities in the form of import/export relationships, 
international subsidies or joint ventures, trademark and/or licensing agreements (Lu, and Beamish 2006; Ulubasoglu, Akdis, and Kok 2009). The primary motivation of these endeavors is penetration into new markets and expansion, either through reaching new customers abroad or offering foreign products to the local customers (Osborne, and Hagedoorn 1997). However, in non-local service partnerships, the firms have different goals; they aim to increase their resource utilization efficiency for serving the existing customers by accessing non-local resources. Although pointing to the international activities, internationalization literature do not address IT SMEs' use of non-local partnerships for joint IT service provision. Our study aims to fill that gap in the literature.

Distance can cause friction between partners; thus, the non-local partnerships may impose additional challenges for the resource-constrained SMEs. For example, the SMEs must invest in fixed costs to learn about foreign environments, communicate at long distances, and negotiate with national governments (Gomess-Casseres 1997). Spatial distance might impede the development of trust that substitutes for formal governance mechanisms in SME relationships (Hoffmann, and Schlosser 2001; Bierly III, and Gallagher 2007). Moreover, since the SMEs are accustomed to communication via informal channels in an ad-hoc manner instead of scheduled meetings, formalized status reports, or structured briefings (Ekanem, and Smallbone 2007); they might experience problems in coordination over distance. Nevertheless, it is likely that the SMEs engaged in non-local cooperation have overcome these challenges under some circumstances. Neither the SME nor the internationalization literature sheds light on these enablers.

In sum, in this exploratory research, we analyze how the spatial distance affects IT SMEs' cooperation with other IT firms for joint service provision, and which factors narrow the "distance" between partners, enable trust building, and enhance cooperation in the absence of geographical proximity. Our research objective is to develop a deeper understanding of this divergent firm behavior and to contribute to the SME and alliance literature. Equally important, the study has practical implications, providing a decision framework to the IT SMEs' decision makers. This 
framework will aid managers in assessing the feasibility of non-local partnerships and help them tailor partnership strategies according to the context.

The remainder of this paper is organized as follows: the next section presents the theoretical background of partnerships in the SME context, particularly non-local IT service partnerships, and discusses the possibility of IT SMEs' engagement in such partnerships. Section 3 explains the research methodology and Section 4 presents the findings. Afterwards, we discuss our findings in the light of the literature and present the propositions and a research framework. We conclude with implications for research and practice.

\section{Theoretical Foundation}

\subsection{SMEs and Partnerships}

SMEs are the engine of the economy and the IT industry. These firms are characterized by fewer employees and functional divisions, limited resource endowment, constrained internal resources and external relationships, and lack of legitimacy compared to their larger peers (Hoffmann, and Schlosser 2001; Das, and He 2006). They have less resource slacks and small buffers to deal with mistakes and challenges (Wiklund, and Shepherd 2009). Due to these constraints, it is crucial for them to access and acquire complementary resources via collaboration, including innovation creation and commercialization (Street, and Cameron 2007; Olander, Hurmelinna-Laukkanen, and Mähönen 2009). For the same reasons, however, it is more difficult for them to safeguard their critical assets against partners' opportunistic behaviors. Hence, they are more concerned about the loss of technological assets (Narula 2004) and more risk averse in interfirm relationships.

The SMEs do have some advantages in partnerships. Their lean organizational structure enables fast and simple decision making, and rapid and informal information flows. As a result, they can integrate informal organizational routines effectively for fast and flexible coordination with the 
partners (Olander et al. 2009). Compared to larger firms, the SMEs are more adaptive and responsive to market requirements and emerging opportunities (Hannah, and Walsh 2008; Olander et al. 2009).

In the SME context, the partnerships are instrumental external sources to access markets, resources, information, and capital (van Gils, and Zwart 2009). These cooperative arrangements provide the SMEs access to resources that would otherwise take years to build internally, thereby buffering a firm from the hazards of young age (Baum et al. 2000). With resource enhancement, the SMEs can achieve efficiency gains, including decreasing operational costs and increasing service quality. By exchanging business leads, firms utilize partners as additional sales and marketing channels (Gulati, Lavie, and Singh 2009). Moreover, the partnerships serve as information channels to rapidly acquire market information so that SMEs can effectively deal with uncertainties and respond to market requirements (Lawson, Moore, Keeble, Lawton, and Wilkinson 1994). All of these factors indicate that the partnerships can be a pivotal mechanism for SMEs' growth.

Previous research posits that, in the technology domain, the survival of the SMEs depends more on their ability to access external resources (Baum et al. 2000). The partnerships are crucial due to the high level of uncertainty in technologies and markets, and the SMEs' interdependency on other technology firms (Moensted 2007). By cooperating, these firms can reduce the uncertainty inherent in dynamic environments (Teece 1997; Lorenzoni, and Lippatini 1999) as well as maintain focus on their core businesses while complementing their services with other IT firms.

\subsection{IT Service Provision and Technology Partnerships}

Partnerships are also essential for IT service provision due to the nature of IT products and services. IT systems consist of interdependent, bundled components; very few can be offered on a stand-alone basis (de Laigue 2004). As the number of IT systems, platforms, or applications implemented in an environment increases, so does the need for integration across them (Iansiti, and Richards 2006). Additionally, the demand for IT services is not uniform; it varies substantially along 
a spectrum of services, ranging from the most basic to very sophisticated. This broad scope necessitates a high level of heterogeneity in terms of underlying technologies and architectures. Consequently, the partnerships formed for IT service provision can be characterized by complex interactions, high levels of asset specificity, and mutual dependence between partnering firms (Gereffi, Humphrey, and Sturgeon 2003).

The literature defines technology partnerships or alliances as forms of interfirm cooperation where the partners are involved in a joint innovative activity or technology exchange for a variety of purposes, e.g., to develop new technology or products or to reduce technological uncertainty (Cantwell, and Colombo 2007; Hagedoorn et al., 2007). The focus of these partnerships is innovation, knowledge exchange, and product development; the partnering firms have a long-term perspective on product-market positioning (Verspagen, and Dusyters 2004; Rothaermal, and Deeds 2006). On another note, BarNir and Smith (2002) distinguish technology/manufacturing alliances from support alliances based on underlying activities and the partnering firms' motivations. In technology/manufacturing alliances, the partners are motivated by future opportunities such as new product/technology development; thus, they endow the alliance with financial investments and longterm commitments. In support alliances, the partners cooperate to jointly perform some business or administrative activity such as sales, advertising, marketing, or training; the main motivation is cost reduction through resource sharing (BarNir, and Smith 2002).

Our study focuses on the partnerships between technology firms that aim to jointly implement and/or maintain IT products/services to customers. The partners' main motivation is access to external complementary resources to leverage their existing skills; the value in the partnership is created by the efficient co-exploitation of both parties' resources (Parmigiani, and Rivera-Santos 2011). For resource-constrained IT SMEs, co-exploitation is a strategically important cooperative interfirm relationship to be competitive in a dynamic industry. Arguing that this type of 
cooperation is distinguished than the previously studied technology partnerships; hence, we particularly analyze the IT service partnerships in this study.

\subsection{Role of Trust in SME Partnerships}

Trust has been repeatedly underlined as a precondition and a pivotal factor in working relationships (Moeller, and Gamm 2005). It has a central role in the development of buyer-seller relationship models (Skarmeas, and Robson 2008), especially in interactions with unfamiliar and distant actors, e.g. for born-globals (Blomqvist, Hurmelinna-Laukkanen, Nummela, and Saarenketo 2008). Trust refers to faith in the moral integrity produced through interactions among individuals or firms (Ring and van de Ven 1994). It has two dimensions: credibility and benevolence. Credibility connotes the extent to which a firm believes its partner has the required expertise and resources to meet the expectations. Benevolence connotes the extent to which a firm believes its partner has good intentions and will behave in fashion beneficial to both parties (Johnson, Cullen, and Sakano 1996).

Once developed, trust converts uncertainty into risks that can be mitigated, decreases social complexity by bridging incomplete information gaps, reduces opportunistic behavior, and facilitates dispute resolution (Moeller, and Gamm 2005). Partnerships necessarily involve sharing confidential information and so also bear the risk of misuse and disclosure of it. SMEs are more risk averse and vulnerable to adverse effects than larger firms; therefore, trust becomes crucial to mitigate risks associated with partnerships (Hoffmann, and Schlosser 2001; Bierly III, and Gallagher 2007). Trust enables efficient interactions by increasing the efficiency and flexibility of decision-making (Moeller, and Gamm 2005; Li, Eden, Hitt, and Ireland 2008). Moreover, it provides partners with a competitive advantage; it facilitates investments in relationship assets, encourages information sharing, and generally lowers transaction costs (Zaheer, McEvily, and Perrone 1998).

The degree of trust between partners affects the governance structure in the partnerships (Gulati 1995; Bierly III, and Gallagher 2007). In other words, trust substitutes for hierarchical 
contracts in interfirm relationships and serves as an alternative control mechanism particularly under resource deficiency (Gulati 1995; Gulati, and Singh 1998). Firms with limited resources rely more on building trust with partners than on setting a hierarchical structure and allocating additional resources to govern the partnership (Bierly III, and Gallagher 2007; van Gils, and Zwart 2009). Thus, we argue that the SMEs make partnership-related decisions, including non-local partnership formation, through the trust lens.

\subsection{Role of Geographical Proximity in SME Partnerships}

One of the facilitators of trust building is geographical proximity between partners (Petruzzelli et al. 2007; Belso-Martinez 2010). Geographical proximity favors frequent, repeated, informal information contacts, such as face-to-face (FTF) interactions that facilitate the exchange of tacit knowledge (Maskell 2001; Gordon, and McCann 2005). FTF is a rich communication medium; it provides both the capacity and the bandwidth required to process complex and subjective messages (Trevino, Lengel, Bodensteiner, Gerloff, and Muir 1990). In the early stages of a relationship, when there is much information to acquire and process, FTF contact facilitates trust development.

Similarly, collocation in a location-based cluster, thus geographical proximity, has long been highlighted as crucial by both strategy and economic geography researchers (Presutti, Boari, and Majocchi 2011). Firms concentrated in a space benefit from urbanization and localization advantages; especially for startups, geographical proximity increases firms' exposure to potential knowledge spillovers (Audretsch, and Lehmann 2006; Stuart, and Sorenson 2003) for knowledge acquisition, exploitation, and exchange purposes. On the other hand, the research indicates that geographical proximity is not sufficient to reinforce knowledge acquisition and exploitation by collocated startups (Rallet, and Torre 2000; Boschma 2005). Being collocated might in fact constrain, rather than enable, learning for startups due to lock-in (Nooteboom 2000) or “overembeddedness” (Uzzi 1997), inhibiting firms from access to external sources of knowledge. 
Nevertheless, the SMEs, especially those in high-tech industries, tend to be located in clusters (Gordon, and McCann 2005; Meyer 2006).

The ease of trust development, knowledge acquisition, exploitation and exchange, coupled with cost advantages encourage SMEs to cooperate with geographically proximate, collocated (i.e. local) firms. The local partner preference might be associated with SMEs' lean organizational structure and practices as well. Local partnerships offer convenience via ad-hoc, spontaneous, and less costly communication, such as FTF. Thus, these firms tend to form local partnerships (Torre, and Rallet 2005).

\subsection{Non-local IT Service Partnerships}

Regardless of the type of partnership, there are organizational, cultural, and cognitive distances between partners; partnerships between distant firms (non-local partnerships) add a physical dimension to these gaps. Distance is presented mostly as a problem in partnerships; it amplifies the challenges associated with information exchange and coordination (Rao 2004; Cramton, and Webber 2005). Thus, the friction negatively affects knowledge transfer, coordination, and project management and thus impedes trust development between partners (Carmel, and Agarwal 2001).

Developing trust in international exchange relationships, e.g. technology partnerships, import/export, or distribution channel relationships, is more challenging compared to relational exchanges in the domestic context (Skarmeas, and Katsikeas 2001; Katsikeas, Skarmeas, and Bello 2009). The researchers attribute this phenomenon to the existence of "psychological distance" (Johanson, and Vahlne 1990), that is, differences between partners in terms of culture, language, economic, and legal systems, accepted business practices, and technical infrastructure (Heeks, Krishna, Nicholson, and Sahay 2001; Carmel, and Agarwal 2001). The partners from dissimilar environments may have different reference frames and incompatible expectations regarding business operations (Zaheer, and Zaheer 2006). Cumulatively, these challenges might magnify existing 
coordination and control problems directly and indirectly through their negative effects on communication (Carmel, and Agarwal 2001) and eventually trust development (Gulati 1995; Katsikeas et al. 2009).

Despite these challenges, in the IT service provision context, non-local partnerships can grant significant advantages. For instance, global sourcing offers benefits such as cost saving, access to a larger skill pool, exploitation of follow-the-sun development, and compensation for lack of internal capabilities (Rao 2004). Resource-constrained SMEs can utilize non-local partnerships as a growth strategy. By tapping into a wider skill pool, they become less dependent on local resources and can grow with lower investment in internal talent. They can optimize costs by leveraging differentials across regions, especially through offshoring. Consequently, they can become more competitive in a dynamic market. The empirical study presented in the next section explores this phenomenon.

\section{Methods}

This research is an exploratory field study aiming to analyze the relationships between focal constructs rather than making claims for causality. In organizational decision-making, the decision is a construct in the eye of the observer, which might not be properly measured by the quantitative manifestation (Langley, Mintzberg, Pitcher, Posada, and Saint-Macary 1995). A qualitative approach enables gathering context-rich data on an emergent phenomenon and reflecting the interpretations of those experiencing it into theory building effectively (Miles, and Huberman 1994). Our goal is to contribute to theory development on IT SMEs' non-local partnership strategies rather than theory testing; thus, we have employed a qualitative approach.

\subsection{Sampling and Recruitment}

The population of the study includes the SMEs operating in various IT industry segments, such as IT consulting, software development, network and hardware services, and IT operations. 
The Office of Advocacy of the US SBA identifies IT SMEs based on their average annual receipts. ${ }^{1}$ Since the revenues are confidential for privately-held SMEs, we adopted the European Commission for Enterprise and Industry's approach based on the number of employees. ${ }^{2}$ This typology classifies firms with less than ten employees as micro, 11 - 50 employees as small, and $51-250$ employees as medium. Thus, we limited the firm size to those with 250 employees or fewer. All study participants are located in Chicago Illinois USA Metropolitan Area.

Our sampling strategy was purposeful rather than random or stratified. Guided by our research question, our sample firms had to offer enough similar aspects so that there would be some comparable properties (Miles and Huberman 1994). Our strategy required that the participants were the senior managers of IT firms representing different segments within the industry; that the firms had fewer than 250 full time employees to be classified as an SME; and that they were located and operative within the same location, i.e. the Chicago Metropolitan Area. We promoted the participation via e-mails and periodic announcements to technology groups (such as Illinois Technology Association and Society for Information Management) and social networking sites (such as Chicago Technology Network, Technology Leaders Association in LinkedIn, Tech Cocktail). We did not limit the participant firms based on their existing partnerships; instead, we preferred that the partnership types emerged from the data. Having validated the firms according to the sample criteria above, we only interviewed those eligible.

Ultimately, the sample contained 19 IT firms (five micro, nine small, and five medium-sized firms), with the oldest established in 1973 and the newest in 2008. The majority of the firms were active in software development and IT consulting (nine and five respectively). In the software development segment, seven firms provided customized solutions such as ERP, Microsoft and Web

\footnotetext{
${ }^{1}$ Source: http://www.sba.gov/content/summary-size-standards-industry

${ }^{2}$ Source : http://ec.europa.eu/enterprise/enterprise_policy/sme_definition/index_en.htm
} 
applications; two firms were suppliers of commoditized solutions ( $\mathrm{SaaS}^{3}$ and Desktop applications). Four other firms provided IT operation, infrastructure, and security services; one firm acted as a full IT service provider for both software development and infrastructure services. All of the firms were headquartered in Chicago except one that had presence in both Chicago and Ann Arbor, MI. The demographics indicate that the diversity across IT subsegments is fairly represented in the sample (Table 1).

*****Insert Table 1 about here $* * * *$

\subsection{Data Collection}

Firm behavior is best reflected by the opinions of the senior executives responsible for strategy development and implementation; there is no perfect proxy or secondary data on firm behavior (Schreiner, Kale, and Corsten 2009). Thus, we relied on key informants' opinions to collect firm-level data. Data was collected via semi-structured interviews with senior managers fulfilling two criteria: (1) the possession of sufficient knowledge on the firm's partnership strategies and the behavior, and (2) adequate involvement in firm's partnership activities. Fourteen of the interviewees were founders of the firms and still in active duty, whereas five of them held executive positions only. Seventeen interviewees were male and two female.

For data collection, we developed a semi-structured interview protocol in accordance with the qualitative data collection principles such as interviewing approach, phrasing and sequencing of the questions, probes and follow-up questions, and helping the respondents develop information (Patton 2002). The protocol consisted of three sections. The first section contained questions on the firm profile such as size, age, location, services and products, and customer information. The second section inquired about SME partnership concepts, such as definition, types, and role of partnerships in the IT industry in general and for the firm in particular. The third section asked open-ended

\footnotetext{
${ }^{3}$ Software as a Service
} 
questions about the firm's partnership choices and the practices in terms of IT service provisioning. We placed a particular emphasis on (1) the descriptions of local and non-local partnerships, (2) the challenges experienced in non-local partnerships, (3) the ways the firms overcame these challenges, and (4) other enablers of non-local partnership formation. The interview protocol was reviewed and refined by the peer researchers and the practitioners (See Appendix A for a sample of the interview questions).

The participants were sent the interview protocol in advance. Before the interviews, the first author reviewed corporate web-pages, news databases, and LinkedIn profiles to acquire information about the firm. Most interviews were conducted on the phone as per the participants' preference ${ }^{4}$; one was held at the participant's office. The interviews were digitally recorded, except one that could not be retrieved due to the malfunction of the recorder. This interview was analyzed based on the interview notes. The recorded interviews were transcribed verbatim for analysis and archival purposes; one of the interviews could be only partially transcribed due to background noise.

\subsection{Data Analysis}

For data analysis, we employed explanation-building, "a form of pattern-matching in which the analysis of the case study is carried out by building a textual explanation of the case" (Miles and Huberman 1994). We have analyzed the interview transcripts, the case notes, and firm information derived from publicly available sources. The unit of analysis was the service partnership formed between IT firms to jointly provide IT service to the customers.

We created an initial coding scheme based on the interview questions and began analyzing the partnerships and their contexts (such as type of IT service jointly provided, customer and partner location, as well as benefits and challenges associated with the location). Following the guidelines for naturalistic inquiry (Lincoln and Guba 1985) and constant comparison techniques (Glaser and

\footnotetext{
${ }^{4}$ In all but one company, respondents expressed significant preference for telephone interviews as this method was perceived to be less disruptive.
} 
Strauss 1967), we have inductively analyzed the data as we collected it. While we were coding the data, some new themes emerged and some others converged. Accordingly, we modified the coding scheme and recoded the interviews for consistency purposes (Miles, and Huberman 1994).

Our data analysis consisted of a process where we searched for common patterns and themes in the data. At the same time, we noted themes specific to a firm (such as unique service offerings) to evaluate the contextual impact on the phenomenon. First, we identified the initial concepts in the data and then grouped them into first order concepts for non-local partnership challenges, coping strategies and other enablers discussed by the interviewees. Next, we compared and contrasted these concept categories to further explore the relationships within and across them; this approach facilitated aggregating them into higher order themes. We then gathered similar themes into overarching aggregate dimensions. Finally, for each dimension, we matched the concepts represented by the themes with the definitions in the literature to identify overarching constructs ${ }^{5}$. This analysis process was not linear but, instead, we continued until we had a clear grasp of the emerging theoretical relationships in the data.

We followed the same process for each partnership activity (such as partner search and selection, knowledge transfer, coordination and governance) that was reported as having challenges in non-local partnerships. Having identified the first order concepts related to partnership activities, we grouped them into second order themes as organizational routines. Afterwards, we further aggregated these routines into an overarching construct as firm's alliance capability. The analysis unfolded an additional aggregate dimension and a construct that enabled non-local partnerships: organizational proximity between partners. Finally, IT service characteristics manifested the construct IT service type. These constructs set the basis of our research framework. The outcome of the data analysis, i.e. the data structure is illustrated in Figure 1.

\footnotetext{
${ }^{5}$ The theoretical definitions of the main constructs are presented in the discussion section.
} 
***Insert Figure 1 about here***

\section{Results}

Data analysis revealed that partnerships in general were common and indispensable in the IT SME world; only two of the 19 firms we investigated were not engaged in any kind of partnerships. The majority of the participants (14 out of 17) reported being partnered with other IT firms for joint service provision, i.e. service partnerships. ${ }^{6}$ The remainder of our analysis is focused on the 14 firms reporting service partnerships.

The main motivation of the firms engaged in service partnerships was to access external resources. By doing so, they expanded their limited resource base, either by qualification or quantity, and could complement or supplement their services. For example, in software development and IT consulting domains, service provisioning necessitates a gamut of development technologies and paradigms that require different development, design, or analysis skill sets. If the firms have not developed this expertise, they chose to form partnerships with other IT firms to supplement their teams. Likewise, for IT operations and infrastructure firms, when a higher level specialization (e.g. security) was required, the firms cooperated with IT firms providing this service. The partnerships enabled the SMEs to stay focused on their core capabilities and specialization while still offering customers a broad range of services.

"That's the value of partnership too is that we can be very focused, committed, the customer tends to reward that." Participant 10

Another equally important motivation was the minimization of personnel costs. Especially in a fluctuating economy, where demand was difficult to forecast, partnerships and subcontracting offered firms the flexibility to access the "right talent" at the "right time" (Participant 14). Last, but

\footnotetext{
${ }^{6}$ These three participants reported other types of cooperation with IT firms (such as cross-referrals to customers), which did not involve service provision component. We observed that the firms that did not need have any service partnerships had either unique product/service offerings or shelf-products: one of them provided niche consulting services, the other two offered commoditized development services such as SaaS and desktop applications. Therefore, they might not need to access external resources and thus did not engage in service partnerships.
} 
not the least, the SMEs considered their service partners as additional sales and marketing channels. The partners offering complementary products and services supported each other in new business generation, referring customers to each other and marketing their services together.

\subsection{Local vs. Non-local Service Partnerships}

To answer our research questions, we next report the analysis of the partner location for firms reporting IT service partnerships (see Table 2 for a summary of the findings). With one exception (Firm 1), all firms reported local partners. Firm 1, a micro-sized, start-up IT operations firm, cooperated with helpdesk and network services firms across the US. The participant stated that the firm did not make a strategic choice in favor of non-local partnerships but could not find a suitable local partner at the time of the interview. This comment indicates that local partnerships are not essential for their business.

***Insert Table 2 about here***

Three firms reported local partnerships only: one micro-sized IT operations firm (Firm 9), one small-sized IT infrastructure firm (Firm 5) and one medium-sized software development firm (Firm 12). These firms were motivated by both convenience and cost. The local partners were known and trusted parties owing to network affiliation and community interactions. The partners had more opportunities for FTF contact; thus, there was less friction in communication, coordination, and relationship building. With local partners, the firms could minimize travel, transaction, search, and communication costs. As one participant summarized:

The preference would be that they are local, [ ] just cause it is easier. We don't have to fly anybody in, [local partnership] cuts and keeps costs low. Participant 6

Ten firms were engaged in both local and non-local partnerships, either domestic (six firms) or international (three firms) or both (one firm). In the first group, there were three IT consulting firms, two customized solution development firms, and one security services firm that cooperated with domestic IT firms for consulting, software development, and hosting services. The IT consulting and security services firms needed either software development capabilities 
(complementary) or additional consulting resources (supplementary); the participants stated that location was not a factor in their partner search. The security firm partnered with hosting firms across the US. For this type of service, there was no need for FTF contact, project management, or close coordination with the partners. Thus, the spatial distance between them was not an issue. All of the firms in that group were micro to small-sized.

The firms in the second group partnered with international software development firms. They were established small- to medium-sized firms, performing customized solution development services. Their motivations were access to certified talent, methodology, and niche skills; gaining credibility and international experience; and offering low-cost options to their customers. One participant summarized these motivations as:

And I did this, because it has three advantages: number one, it gave us immediate access to CMM 5 methodology, number two it gave us access to case studies and track records of having delivered projects, because [firm] didn't have a track record of offshore projects [ ] And then three it gave you access to a deep pool of resources that could, that was responsible without a bench. Participant 7

Finally, one medium-sized custom software development firm managed a portfolio of local, domestic, and international partners. This firm utilized each type of partner for different type of IT services: local partners for network and user experience design services, domestic partners for hosting services, and an international partner for software development services.

In summary, the majority of firms had a partnership portfolio consisting of both local and non-local firms. The participants indicated that the type of IT service rendered via the partnership determined the partner's location preference. For system-driven and remotely-rendered procedural services, such as hosting and helpdesk services, the firms were location-agnostic: the firms did not need to interact with the partner frequently so they could easily communicate over the Internet or by phone and e-mail. They were thus more open to distant cooperation and did not identify substantial distance-related problems. As stated by one participant:

Well, it doesn't matter where the hosting is, if it is next door to you or if it is across the country. [ ] The location is not a factor. I don't care what these servers look like, I don't need to visit them, I don't need to talk to anyone. Participant 3 
Alternatively, for creative services such as user experience design and software development, the participants consistently argued that the distance would impede the quality of communication and coordination and ultimately the quality of the service. Similarly, for services requiring physical presence and immediate intervention, such as infrastructure design and management, firms preferred a partner close to the customer's premises, mostly local IT firms.

All of our projects are in combination of, all of our projects involve a creative component, we are doing design. Delivering creative services is very emotional. It takes a lot of conversations, and the conversations they are face to face. Participant 3

\subsection{Non-local Service Partnership Challenges and Firms' Strategies}

The non-local partnerships were not hassle-free. From the participants' narratives, it became apparent that the distance aggravated the challenges and complexities already existing in partnerships. Major problems reported were related to partner search, communication, knowledge transfer, coordination, and governance activities.

The firms did not possess the resources to search for, analyze, and evaluate potential nonlocal partners, especially the international ones. Partner search beyond their territory was a significant challenge. Communication problems associated with time zones differences and availability were disruptive. Due to spatial distance, the partners lacked FTF contact and had to utilize less rich, asymmetric and asynchronous media, such as e-mail and phone. In international partnerships, the firms faced additional challenges such as cultural differences and language barriers. Transferring the service component to a non-local partner required more specific and clear documentation compared to a local one; the firms had to allocate excessive time and effort in knowledge and information transfer. Moreover, these efforts caused an additional internal administrative burden. As a result, coordination with non-local partners was inefficient and the firms were concerned about the quality of service delivery. Last but not least, one of the firms had a channel conflict with its offshore partner who had a presence in the US; large offshore firms can 
easily bypass the focal firm and deliver directly to the customer. Table 3 summarizes challenges experienced in non-local partnerships, including sample quotes from interviewees.

***Insert Table 3 about here***

To overcome these challenges, the participants have created routines and mechanisms for partner search and selection, knowledge transfer, coordination, and governance activities. These organizational routines were not formal best practices; rather, they were context-specific, informal, and repetitive patterns of practices tailored to the senior managers' orientation and background, similar to dynamic capabilities. For example, especially for international partnerships, the firms adopted an iterative partner selection process to evaluate a distant firm with relatively less information.

The software and consulting firms modified their existing software development and project management processes to address the requirements of distant cooperation, including extended quality assurance steps. The firm's existing project management skills and the leadership's international consulting experience facilitated and shaped these modifications. Especially in software development projects, the partners needed to exchange detailed business and technical information; a substantial portion of that exchange comprised tacit knowledge. In non-local partnerships, crystallization of the business requirements was crucial to convey customer needs correctly to a distant service provider that did not have many opportunities to contact the customer. To address that, firms prepared more detailed functional and technical specifications with clear instructions than they would for local partners. They also embedded additional quality assurance steps in their testing processes to remedy potential quality issues.

In terms of communication, the participants utilized multiple media, such as e-mails, conference calls, and video conferencing, to substitute for FTF contact, e.g. in-person meetings. They adapted the media according to the prevailing context and content. Finally, to avoid customer ownership conflicts, firms enhanced their negotiation and conflict management skills; in addition to 
trust, they governed these relationships via strong contracts to avoid partners' direct solicitation to the customers. Table 4 presents examples of the organizational routines developed by the participants to overcome the challenges in non-local partnerships, including sample quotes from interviewees.

\section{***Insert Table 4 about here***}

In conclusion, cooperation with a non-local partner occurred more smoothly with these mechanisms in place. These findings support the argument that IT SMEs engaged in non-local service partnerships have developed dynamic capabilities corresponding to each step in partnership formation, even though they were constrained in terms of resources.

\subsection{Non-spatial Proximity}

In addition to the above-mentioned strategies, our interviews revealed other factors that narrowed the spatial distance between partners and enabled trust building. In particular, shared personal and technology networks and the existence of local representation by partners created a type of proximity between geographically distant partners and facilitated non-local partnership formation. Affiliation via firm- or individual-level networks, especially senior management's networks and connections, played an important role in inter-firm relationships. For IT consulting firms that cooperated with other non-local consulting firms, the main enablers were senior managers' orientation towards distant cooperation and their nation-wide professional networks. As one of the participants explained:

Well, geography isn't that critical. You know if you again look at the evolution of our business, relationships and the networks we participate, a lot of them we build out of Chicago market. I have one guy that does CIO advisory working with us, that is in Boston, another one in Louisville that we are serving the field out there, you know it is mainly the growth and the evolution of relationships with people that myself or my partner worked over the years.

Participant 14

Another influential factor was shared cultural, national, or ethnical backgrounds between employees at partnering firms; these ties acted as an intermediary between the firms as well.

One of our employees was born in Pakistan. So he actually has through his family and friends back in Pakistan connections to various companies. So, it helped from a cultural standpoint that he managed the whole thing. Participant 11 
Finally, the non-local partner's representation at the focal firm's geographic location, such as a sales or marketing office, provided support for trust building. The expectation was not that local representatives performed full functionalities; instead they acted as a bridge between the different cultures, a communication interface, and a boundary spanner. Several participants claimed that the local representation, while limited, helped overcome the communication- and coordination-related challenges to a certain extent and led to consideration of non-local partnership formation.

\section{Discussion}

This exploratory research analyzes how the spatial distance affects IT SMEs' engagement in service partnerships with non-local (i.e. domestic or international) IT firms, and the factors narrowing the gap between partners to enable satisfactory cooperation. Previous research underlines the importance of trust in SME interfirm relationships and posits that, due to their characteristics, SMEs utilize trust as a risk mitigation and a governance mechanism (Hoffmann, and Schlosser 2001; BarNir, and Smith 2002; van Gils, and Zwart 2009). Geographically proximate firms have more opportunities for FTF contact, which, in turn, facilitates trust building (Petruzzelli et al. 2007; BelsoMartinez 2010). Therefore, SMEs tend to form partnerships with geographically proximate, local firms due to the ease of trust building and convenience (Torre and Rallet, 2005). Though acknowledging this tendency in data, our findings provide empirical evidence that, indeed, some SMEs can build trust and convenience with distant partners while some others still prefer local partners.

The SME literature lists some organizational variables (such as age, size, assets, management practices, culture, and position in the industry) as the determinants of partnership formation (Hannah, and Walsh 2008; van Gils, and Zwart 2009; Belso-Martinez 2010). Although these factors are influential on firm behavior in general, our data suggest that these characteristics do not necessarily facilitate the formation of non-local service partnerships. For example, while some 
medium-sized firms preferred local partnerships, some smaller ones were actively engaged in nonlocal partnerships. Likewise, some mature firms tended to form only local partnerships whereas some younger ones formed or considered forming non-local partnerships.

The findings confirm the literature positing that spatial distance and cultural differences between partners impede trust development in international relationships, e.g. importer/exporter relationships (Skarmeas, and Katsikeas 2001; Katsikeas et al. 2009). At the same time, several facilitators enabling non-local partnerships emerge from data analysis. We discuss these facilitators as follows. First, we suggest that firm's alliance capabilities (Kale, Dyer, and Singh 2002; Heimeriks, and Duysters 2007, Schreiner et al. 2009), in the form of informal routines and procedures, matter more than other firm properties in forming non-local service partnerships. Second, the findings highlight the importance of organizational proximities (Torre, and Rallet 2005; Oerlemans, and Meeus 2005; Knoben, and Oerlemans 2006) in the absence of geographical proximity. Finally, data suggests that the type of IT service provided via the partnership drives IT SMEs' partnership choices, an aspect overlooked so far in the literature. Following this discussion, we develop propositions for future research and present a research framework for non-local IT service partnerships in the SME context.

\subsection{Alliance Capabilities}

Our data show that the IT SMEs, which have adopted internal methodologies for software development and project management can effectively manage distance-related challenges in partnerships. Similarly, the firms that have developed partnership-related routines are more open to non-local partnerships. These organizational routines represent the alliance capability defined as "the ability to internalize alliance management knowledge acquired via interactions with other firms" (Eisenhardt, and Martin 2000; Heimeriks, and Duysters 2007, Schreiner et al. 2009). Similarly, SME internationalization (Weerawardena et al. 2007) and global sourcing/offshoring 
literature (Ranganathan, and Balaji 2007) briefly note the importance of developing organizational capabilities.

Previous literature describes the alliance capability with dedicated alliance functions, established procedures, and tools in a large firm context (Kale et al. 2002; Heimeriks, and Duysters 2007). Our analysis indicates that the IT SMEs do not possess dedicated functions, established processes, and specific tools; instead their partnership routines are rather informal and unstructured. Nevertheless, these routines are unique to the firm and represent a firm's dynamic capabilities.

In order to elaborate these routines, we referred to the alliance management capability conceptualization (Schreiner et al. 2009) with three distinct dimensions: 1) coordination, 2) communication, and 3) bonding with the partner. The coordination dimension encompasses integration of each task to the overall project and orchestration of the integration activities across all business units (Carmel, and Agarwal 2001). In a partnership context, it captures identification of task requirements, specification of working procedures, and determination of roles and responsibilities in task execution for each partner (Espinosa, Sandra, Robert, and Herbsleb 2007; Schreiner et al. 2009). The communication capability represents the skills to convey relevant knowledge and information between partners in a timely, accurate, and complete manner (Schreiner et al. 2009). It includes deploying a variety of formal and informal communication modes, choosing and adjusting them according to the context and content. Finally, the bonding capability includes activities like being proactively responsive to partners' concerns and needs, remaining in frequent contact, and attending seriously to partner's views, ideas, and circumstances (Schreiner et al. 2009). These dimensions facilitate development of shared understanding on roles and responsibilities, construction of shared collaboration models, management of conflicts, and trust development (Schreiner et al. 2009).

Our analysis points out that the IT SMEs equipped with project management skills and established internal development processes achieve better coordination with their non-local partners. 
In terms of communication, the distant partners have fewer opportunities for FTF contact. Thus, they have to use less rich information and communication technologies (ICT) such as e-mail, conference call, video conference, and chat. This limitation leads firms to develop and implement communication strategies different than the ones in local partnerships, including media choice. Furthermore, in non-local partnerships, the firms need to recognize the cultural differences with partners and adapt their communication style, including the tone and the language, accordingly. The empirical findings confirm the role of cultural sensitivity on trust development and relationship quality in international distribution channels (Batonda, and Perry 2003; Skarmeas and Robson 2008).

In addition to coordination and communication, our analysis captures several other alliance routines specific to IT service provision: IT service assessment, analysis and specification preparation, knowledge transfer between partners, and quality assurance. The disadvantage of spatial distance seems to be strongly evident in the case of tacit, complex, and non-codified forms of knowledge (Ahuja 2000). Knowledge transfer capability, the ability to transfer task-related tacit knowledge to the partner in a timely manner and in sufficiently-detailed manner is reported as crucial especially for the development of projects. This transfer comprises both the preparation (conversion of the knowledge or information from tacit to explicit format) and the transmission of knowledge via appropriate mechanisms. Since FTF contact is limited, the main knowledge transfer mechanism is the project and task documentation, such as project plans, functional and technical specifications, test case scenarios, and instructions to the developers. Our findings suggest that the larger the physical and cultural distance between partners, the more structured and standard the documentation should be.

Based on the abovementioned premises, we posit that a firm's alliance capabilities narrow the gap between distant partners, enabling trust development over distance and facilitating non-local partnership formation for joint service provision. 
P1: IT SMEs equipped with alliance capabilities show a greater propensity to establish nonlocal service partnerships compared to firms lacking relevant capabilities.

Moreover, our findings highlight the learning curve in alliance capability development. Once the firms are engaged in repetitive non-local partnerships, they regenerate partnership knowledge. Consequently, this experience contributes to the renewal or the modification of the existing capabilities or the development of new capabilities. This finding is in line with the literature on organizational learning and capability development (Dyer, and Singh 1998; Eisenhardt, and Martin 2000; Heimeriks, and Duysters 2007; Schreiner et al. 2009).

P2: IT SMEs that gain experience in non-local partnerships are more likely to develop relevant alliance capabilities which increase the likelihood of forming and continuing non-local partnerships.

\subsection{Organizational Proximities between Partners}

The literature posits that in the absence of geographical proximity, other intangible dimensions of proximity may act as substitutes (Oerlemans, and Meeus 2005; Torre, and Rallet 2005; Knoben, and Oerlemans 2006). In this case, trust can be built through firm- and individuallevel networks in the presence of cultural and organizational similarities (Bierly III and Gallagher, 2007), i.e. organizational proximities. Our analysis underlines the role of organizational proximities in narrowing the distance between non-local partners in joint IT service provision.

Organizational proximity is defined as "belonging to the same space of references" and manifested by shared representations, values, norms, standards, culture, and work practices (Torre, and Rallet 2005; Oerlemans, and Meeus 2005; Knoben, and Oerlemans 2006). This type of proximity can be created through affiliation with firm- and individual-level social networks (Torre, and Rallet 2005; Bierly III, and Gallagher 2007). As a member of such networks, firms build trust more easily with other members, compared to outsiders (Hagedoorn et al., 2007). Our data suggest that firm- or individual-level networks, such as communities of practice, technology associations, and user groups, provide platforms to share representations, norms, standards, and work practices 
among its members. If these networks cross regional and national boundaries, the IT SMEs have greater opportunities to seek, find, and interact with non-local partners. Another example of firmlevel affiliation is partnership programs or technology platforms organized by vendors and technology firms (e.g. Microsoft, IBM) aiming to provide a common platform for members. This phenomenon is a frequent practice in IT industry. Belonging to the same platform enables trust building between partners, local or non-local, and efficient communication. Similar affiliations are built at the individual level: for example, through senior managements' personal and professional networks and through shared national, cultural, or ethnic backgrounds of team members. Thus, these networks offer convenient platforms to facilitate and foster interfirm relationships for IT SMEs.

Organizational proximity can also be achieved if the non-local partner has a representation in the focal firm's locality. Our findings suggest that even though limited in terms of the functionalities, this presence provides a convenience for SMEs, especially for the offshore partnerships. In that situation, the partners have the opportunity to understand each other's environment and culture through the representative's eye. Thus, the local representation provides a comfort zone to both parties and acts as a proxy for the geographical proximity between the partners. We expect that organizational proximity will be most beneficial to firms engaging in people-intensive creative tasks, which require dense and rich interactions between partners. We posit that the above-mentioned aspects facilitate trust building and non-local partnership formation because they provide organizational proximity between distant IT firms.

P3: IT SMEs having organizational proximities with their non-local partners show a greater propensity to form non-local service

\subsection{Influence of IT Service Type}

A novel finding of this exploratory study is the impact of IT service type on partnership choices. Our data analysis suggests that the type of IT service rendered via the partnership shapes how the service is provided and how the partners cooperate with each other, eventually determining 
the partnership choice. For example, for commoditized services (such as hosting), clearly defined tasks (such as testing), and support activities (such as first-level of support), geographical proximity between partners is not essential and fewer distance-related are problems reported: IT SMEs are more likely to partner with non-local firms for such services. On the contrary, for creative services, such as software development, user experience design, and IT consulting, the spatial distance impedes the quality of communication and coordination. Additionally, emerging technologies, such as virtualization and cloud technologies, enable virtual cooperation. Hence, the development paradigms using these technologies (e.g. Ruby on Rails ${ }^{\mathrm{TM}}$ development) or remote deployment activities enable distant cooperation.

To characterize the IT services, we employed Zaheer, Lamin, and Subramani's (2009) typology developed for IT-enabled services. This typology is based on two knowledge characteristics: system vs. people-intensiveness, and routineness vs. creativity. On the one hand, system intensiveness indicates a high level of process automation, which facilitates remote monitoring and execution of an IT service. Data suggest that this characteristic diminishes boundedness to location and the role of geographical proximity between partners: it facilitates formation of non-local partnerships. Examples are data processing, hosting, and network administration services.

On the other hand, the degree of automation in people-intensive services is relatively lower. The provision of these services necessitates interpersonal interactions, specialized skills, and application of knowledge, intuition, and judgment. These services are subcategorized into two groups: people-intensive routine services and people-intensive creative services. The routine or repetitive services can be described in abstract and standard forms and codified in standard operating procedures; service provision often comprises the execution of scripts. These services can be delegated, exchanged, and transferred easily between partners or rendered remotely. The analysis reveals that the partners do not need to interact frequently during service provision, and management 
of interactions is not complicated. Alternatively, people-intensive creative services, such as business analysis, user interface design, custom development, and IT consulting, involve specialized knowledge, expertise, judgment and improvisation. Interactions between partners are dense, especially at the early stages of the partnership. Because of the creative nature of the service, there is substantial ambiguity and uncertainty. Hence, knowledge and information exchange between partners requires rich media, such as FTF contacts, and benefit from geographical proximity. However, IT SMEs equipped with alliance capabilities and/or sharing organizational proximities with the partners tend to engage in non-local service partnerships.

Thus, we posit that the IT service type enables or disables non-local service partnership formation, determining the extent of alliance capabilities and organizational proximities needed.

P4a: IT SMEs are more likely to engage in non-local partnerships to provide system-intensive and people-intensive routine IT services compared to other types of services.

P4b: IT SMEs equipped with alliance capabilities show a greater propensity to establish nonlocal service partnerships to provide people-intensive creative services when compared with firms lacking relevant capabilities.

P4c: IT SMEs organizationally proximate to their partners show a greater propensity to establish non-local service partnerships to provide people-intensive creative services when compared with the firms lacking this proximity.

Figure 2 summarizes the abovementioned propositions.

***Insert Figure 2 about here***

\section{Conclusion}

Partnerships and alliances are well-studied in academia; however, most studies focus on cooperative arrangements formed by or between large or international firms for R\&D or technology development purposes (Hagedoorn et al., 2007; Li et al., 2008; Narula, 2004). Little scholarly attention has been paid to other types of partnerships in the technology domain, such as the partnerships formed for technology service provision, although they are common in the IT industry. 
Similarly, the SMEs are understudied in this technology domain. Moreover, we know that the IT SMEs are engaged in non-local partnerships; however, we do not know what factors enable this cooperation. Analyzing this emerging phenomenon through trust and proximity lenses, this study fills this gap in the literature by exploring the facilitators of IT SMEs' non-local service partnerships.

The theoretical contribution of the study is fourfold. First, distinguishing from other types of technology partnerships, the study conceptualizes IT service partnerships as a cooperative scheme between IT firms to jointly provide service to the market. Second, our study provides empirical evidence that IT SMEs do form service partnerships in the absence of the geographical proximity. Alliance capabilities and organizational proximities between partners compensate for the lack of the geographical proximity, enable trust building over distance, and facilitate the non-local partnership formation. The IT service type is a determinant of this choice; it moderates the extent of the alliance capabilities and the organizational proximities required for a successful cooperation.

This research also challenges the argument that the firm size is a proxy for firm behavior. We posit that the firm's context- specific organizational capabilities (Eisenhardt, and Martin 2000; Heimeriks, and Duysters 2007; Schreiner et al. 2009) play a greater role in non-local cooperation than a firm's size. While previous research conceptualizes the alliance capability by dedicated functions, established procedures, and tools in a large firm context (Kale et al. 2002; Heimeriks, and Duysters 2007), our research suggests that the IT SMEs that lack these structures, can develop informal organizational routines which represent unique alliance capabilities. Fourth, parallel to the organizational learning literature (Anand, and Khanna 2000; Kale, and Singh 2007), we confirm that the capabilities associated with non-local partnerships are developed and excelled through repetitive distant cooperation.

Equally important, our research has practical implications; the study provides a conceptual map for IT SMEs' senior managers who are interested in partnering with non-local IT firms. The 
study unfolds the importance of capability development for the SMEs, rather than the deployment of ICTs or the dedication of extra resources. Additionally, it will be beneficial for IT SMEs that are already engaged or plan to engage in non-local service partnerships to create organizational proximities with distant partners, e.g. become active in technology associations. Another key factor is to consider a non-local partnership as an investment, rather than a service provision relationship, and develop shared values and norms with the partner.

We acknowledge the limitations of our study. The major limitations stem from the method and the extent of data collection. First, data collection relied solely on interviews with the key informants', i.e. founders and senior managers, reports. There were no observation opportunities and the firms were not willing to share the partnership-related documents (such as partnership agreements, meeting minutes, project documents, specifications, etc.) due to confidentiality. Second, the study has a cross-sectional design although we analyzed past experiences and firms' partnerships histories. The two core constructs of the study, capabilities and formation behavior, have pathdependent and evolutionary characteristics, which may not be reflected in our findings.

We believe that several future research avenues might further elaborate the phenomenon and address the limitations. More detailed empirical research is required that can delve into these practices more deeply. For example, researchers could look more closely at firm size to investigate differences in micro, small, and medium firms. Longitudinal case studies will increase our understanding on SMEs' partnership formation and capability development processes. Moreover, the theoretical contribution calls for testing. Researchers should work further on operationalization and measurements of the constructs introduced and test the hypotheses derived from these propositions.

The findings suggest that the IT SMEs consider service partnerships as long-term investments. Considering this perspective, we posit that for the SMEs, it is not the face value of the contract, but the value of the partnership that is more crucial. By conceptualizing and 
operationalizing the partnership value, future research can shed light how this factor impacts SMEs' partnership formation choices. The IT industry offers a rich setting for future research. Iansiti and Richards (2006) describe the IT industry as an economic and social community, an "ecosystem" that constitutes of highly interconnected networks of IT firms, technologies, products, and customers. In the IT industry, there are two critical roles: platform (e.g. Windows, Linux) and application (e.g. SAP) providers.

Our data indicate that these programs provide a foundation to develop shared reference bases, norms, and technology perspectives for its members; hence, they might create organizational proximities between geographically distant IT firms. As a future research alternative, the researchers might be interested in exploring the role of these platforms and the platform providers in IT SMEs' service partnership formation.

Last but not the least; future studies may extend this research by replicating it in different locations. By comparing findings across different settings, such as other urban areas, IT clusters, industrial regions, and technology zones, future research will elaborate the location's role in IT SMEs’ service partnership strategies.

\section{References}

Ahuja, G. (2000). "The Duality of Collaboration: Inducements and Opportunities in the Formation of Interfirm Linkages," Strategic Management Journal, 21, 317-343.

Anand, B.N., and T. Khanna (2000). "Do Firm Learn To Create Value? The Case of Alliances," Strategic Management Journal 21, 295 - 315.

Audretsch, D., and E. Lehmann (2006). "Entrepreneurial Access and Absorption of Knowledge Spillovers: Strategic Board and Managerial Composition," Journal of Small Business Management, 44, 155-166.

Batonda, G. and C. Perry (2003). "Influence of Culture on Relationship Development Processes in Overseas Chinese/Australian Networks," European Journal of Marketing, 37(11/12), 1548-1574.

Baum, A.J., T. Calabrese, and B.S. Silverman (2000). "Don't Go It Alone: Alliance Network Composition and Startups' Performance in Canadian Biotechnology," Strategic Management Journal 21(3), 267 - 294.

BarNir, A., and K.A. Smith (2002). "Interfirm Alliances in the Small Business: The Role of Social Networks," Journal of Small Business Management 40(3), 219-232. 
Belso-Martinez, J.A. (2010). "International Outsourcing and Partner Location in the Spanish Footwear Sector: An Analysis Based in Industrial District SMEs," European Urban and Regional Studies, 17(1), 65-82.

Bierly III, P. E, and S. Gallagher (2007). "Explaining Alliance Partner Selection: Fit, Trust and Strategic Expediency," Long Range Planning 40(2), 134 - 153.

Blomqvist, K., P. Hurmelinna-Laukkanen, N. Nummela, and S. Saarenketo (2008). "The Role of Trust and Contracts in the Internationalization of Technology-intensive Born Globals," Journal of Engineering Technology Management, 25, 123-135.

Boschma, R. A. (2005). "Proximity and Innovation: A Critical Assessment," Regional Studies, 39(1), 61-74.

Cantwell, J., and M.G. Colombo (2007). "Technological and Output Complementarities: Interfirm Cooperation in Information Technology Ventures," Journal of Management and Governance, 4, 117- 147.

Carmel, E., and R. Agarwal (2001). "Tactical Approaches for Alleviating Distance in Global Software Development," IEEE Software, 18(2), 22 - 29.

Casey, K. Information Week. 06/03/2011. http://www.informationweek.com/news/smb/services/229900119, accessed on June 15, 2011.

Contractor, F., J., and P. Lorange (2002). "The Growth of Alliances in the Knowledge-based Economy," International Business Review, 11, 485-502.

Cramton, C.D. and S.S. Webber (2005). "Relationships Among Geographic Dispersion, Team Processes, and Effectiveness in Software Development Work Teams," Journal of Business Research, 58(6), 758-765.

Das, T.K., and I.Y. He (2006). "Entrepreneurial Firms In Search Of Established Partners: Review and Recommendations," International Journal of Entrepreneurial Behavior \& Research, 12(3), $114-143$.

de Laigue, F.J. (2004). "Strategy, Structure and Performance of IT Services firms". Master thesis.

Dudek, S., F. Uebernickel, and W. Brenner (2009). "Challenges in IT Supply Chain Management," Proceedings of the Fifteenth Americas Conference on Information Systems, San Francisco, CA.

Dyer, J.H. and H. Singh (1998). "The Relational View: Cooperative Strategy and Sources of Interorganizational Competitive Advantage," Academy of Management Review, 23(4), 660-670.

Eisenhardt, K. M., and J.A. Martin (2000). "Dynamic Capabilities: What Are They?," Strategic Management Journal, 21, 1105 - 1121.

Ekanem, I., and D. Smallbone (2007). "Learning in Small Manufacturing Firms: The Case of Investment Decision-making Behavior," International Small Business Journal, 25(2), 107-129.

Espinosa, J. A., S.A. Sandra, K. Robert, and J. Herbsleb (2007). "Team Knowledge and Coordination in Geographically Distributed Software Development," Journal of Information Management Systems, 24(1), 135-169.

Glaser, B., and A. Strauss (1967). The Discovery of Grounded Theory. Chicago, IL: Aldine.

Gereffi, G., J. Humphrey, and T. Sturgeon (2003) "The Governance of Global Value Chains," Review of International Political Economy, 12 (1), 78-104.

Gomes-Casseres, B. (1997). “Alliance Strategies of Small Firms,” Small Business Economics, 9, 33 $-44$.

Gordon, I., and P. McCann (2005). "Innovation, Agglomeration and Regional Development," Journal of Economic Geography, 5(5), 523-543.

Gulati, R. (1995). "Does Familiarity Breed Trust? The Implications of Repeated Ties for Contractual Choice in Alliances," Academy of Management Journal, 38(1), 85-112.

Gulati, R., and H. Singh (1998). "The Architecture of Cooperation: Managing Coordination Costs and Appropriation Concerns," Administrative Science Quarterly, 43, 781-814. 
Gulati, R., D. Lavie, and H. Singh (2009). "The Nature of Partnering Experience and The Gains From Alliances," Strategic Management Journal, 30, 1213-1233.

Hagedoorn, J. (1993). "Understanding the Rationale of Strategic Technology Partnering: Interorganizational Modes of Cooperation and Sectoral Differences," Strategic Management Journal, 14(5), 371 - 385.

Hagedoorn, J., W. Letterie, and F. Palm (2007). "Information Value of (un)embedded R\&D Alliances," Working paper, Maastricht University.

Hannah, V. and K. Walsh (2008). "Interfirm Cooperation among Small Manufacturing Firms," International Small Business Journal, 26(3), 299-321.

Heeks, R., S. Krishna, B. Nicholson, and S. Sahay (2001). "Synching or Sinking: Global Software Outsourcing Relationships," IEEE Software, 18(2), 54-60.

Heimeriks, K. H., and G. Duysters (2007). "Alliance Capability as a Mediator between Experience and Alliance Performance: An Empirical Investigation into the Alliance Capability Development Process," Journal of Management Studies, 44(1), 25-49.

Hoffmann W.H., and R. Schlosser (2001). "Success Factors of Strategic Alliances in Small and Medium-Sized Enterprises - An Empirical Survey," Long Range Planning, 34, 357-381.

Iansiti, M., and G.L. Richards (2006). "The Information Technology Ecosystem: Structure, Health and Performance," The Antitrust Bulletin, 51(1), 77-110.

Johanson, J., and J. E. Vahlne (1990). "The Mechanism of Internationalism," International Marketing Review, 7(4), 11-24.

Johnson, J. L., J.B. Cullen, T. Sakano, and H. Takenouchi (1996). "Setting the Stage for Trust and Strategic Integration in Japanese-US Cooperative Alliances," Journal of International Business Studies, 27(5), 981-1004.

Kale, P., J.H. Dyer, and H. Singh (2002). “Alliance Capability, Stock Market Response, and LongTerm Alliance Success: The Role of Alliance Function," Strategic Management Journal, 23, 747-767.

Kale, P., and H. Singh (2007). "Building Firm Capabilities Through Learning: The Role of The Alliance Learning Process In Alliance Capability and Firm-Level Alliance Success," Strategic Management Journal, 28(10), 981-1000.

Katsikeas, C.S., D. Skarmeas, and D.C. Bello (2009). "Developing Successful Trust-based International Exchange Relationships," Journal of International Business Studies, 40, 132-155.

Knoben, J., and L.A.G. Oerlemans (2006). "Proximity and Inter-Organizational Collaboration: A Literature Review," International Journal of Management Reviews, 8(2), 71-89.

Langley, A., H. Mintzberg, P. Pitcher, E. Posada, and J. Saint-Macary (1995). "Opening Up Decision Making: The View from the Black Stool," Organization Science, 6(3), 260-279.

Lawson, C., B. Moore, D. Keeble, H. Lawton Smith, and F. Wilkinson (1994). "Interfirm Links between Regionally Clustered High-Technology SMEs: A Comparison of Cambridge and Oxford Innovation Networks," In New Technology-Based Firms in the 1990s, 181 - 196, Chapter 15.

Li, D., L. Eden, M.A. Hitt, and R.D. Ireland (2008). "Friends, Acquaintances, or Strangers? Partner Selection in R\&D Alliances," Academy of Management Journal, 51(2), 315- 334.

Lincoln, Y., and E. Guba (1985). Naturalistic Inquiry. Beverly Hills, CA: Sage.

Lorenzoni, G. and A. Lipparini (1999). "The Leveraging of Interfirm Relationships as a Distinctive Organizational Capability: A Longitudinal Study," Strategic Management Journal, 20, 317 338.

Lu, J. W., and P.W. Beamish (2006). "Partnering Strategies and Performance of SMEs' International Joint Ventures," Journal of Business Venturing, 21(4), 461-486.

Maskell, P. (2001). "Towards a Knowledge-Based Theory of the Geographical Cluster," Industrial and Corporate Change, 10, 921-943. 
McCann, P. (1995). "Rethinking the Economics of Location and Agglomeration," Urban Studies, 32(3), 563-577.

Meyer, S.P. (2006). A Spatial Analysis of Small- And Medium-Sized Information Technology Firms In Canada and the Importance of Local Connections To Institutions of Higher Education," The Canadian Geographer, 50(1), 114-134.

Miles, M.B., and A.M. Huberman (1994). Qualitative Data Analysis: An Expanded Sourcebook (2 ${ }^{\text {nd }}$ Edition). Thousand Oaks, CA: Sage Publications, Inc.

Mithas, S., and J. Whitaker (2007). "Is the World Flat or Spiky? Information Intensity, Skills and Global Service Disaggregation," Information Systems Research, 18(3), 237-259.

Moeller, K., and N. Gamm (2005). "Partner Selection and Network Performance," paper presented at EMNet-Conference on Economics and Management Networks, Budapest, Hungary.

Moensted, M. (2007). "Strategic Networking in Small High Tech Firms," International Entrepreneurship Management Journal, 3, 15-27.

Nambisan, S. (2002). "Software Firm Evolution and Innovation-orientation," Journal of Engineering and Technology Management, 19 (2), 141-165.

Narula, R. (2004). "R\&D Collaboration By SMEs: New Opportunities and Limitations In The Face of Globalization," Technovation, 24, 153-161.

Nooteboom, B. (2000). "Learning by Interaction: Absorptive Capacity, Cognitive Distance and Governance," Journal of Management and Governance, 4(1-2), 69-92.

Oerlemans, L.A.G., and M.T.H. Meeus (2005). "Do Organizational and Spatial Proximity Impact On Firm Performance?," Regional Studies, 39(1), 89-104.

Olander, H., P. Hurmelinna-Laukkanen, and J. Mähönen (2009). "What's Small Size Got To Do With It? Protection of Intellectual Assets in SMEs," International Journal of Innovation Management, 13(3), 349-370.

Osborn, R., and J. Hagedoorn. (1997). "The Institutionalization and Evolutionary Dynamics of Interorganizational Alliances and Networks," Academy of Management Journal, 40(2), 261-278.

Parmigiani, A., and M. Rivera-Santos (2011). "Clearing a Path Through the Forest: A Meta-Review of Interorganizational Relationships,” Journal of Management, 37, 1108-1136.

Patton, M.Q. (2002). Qualitative Research \& Evaluation Methods ( ${ }^{\text {rd }}$ Edition). Thousand Oaks, CA: Sage Publications. Inc.

Petruzzelli, A.M., V. Albino, and N. Carbonara (2007). "Technology Districts: Proximity and Knowledge Access," Journal of Knowledge Management, 11(5), 98-114.

Presutti, M., C. Boari, and A. Majocchi (2011). "The Importance of Proximity for the Start-Ups' Knowledge Acquisition and Exploitation," Journal of Small Business Management, 49(3), 361389.

Rallet, A., and A. Torre (2000). "Is Geographical Proximity Necessary in the Innovation Networks in the Era of Global Economy?," GeoJournal, 49, 373-380.

Ranganathan, C., and S. Balaji (2007). Critical Capabilities for Offshore Outsourcing of Information Systems, Indiana University, USA. Sprouts: Working Papers on Information Systems, 7:14. http://sprouts.aisnet.org/7-14.

Rao, M.T. (2004). "Key Issues for Global IT Sourcing: Country and Individual Factors," Information Systems Management, 21(3), 16-21.

Ring, P.S., and A.H. van de Ven (1994). "Developmental Processes of Cooperative Interorganizational Relationships," Academy of Management Review, 19(1), 90-118.

Rothaermal, F.T., and D.L. Deeds (2006). "Alliance Type and Alliance Management Capability in High-Technology Ventures," Journal of Business Venturing, 21, 429-460.

Schreiner, M., P. Kale, and D. Corsten (2009). "What Really Is Alliance Management Capability and How Does It Impact Alliance Outcomes And Success?," Strategic Management Journal, 30(13), 1395-1419. 
Scott, A. (2006). "Creative Cities: Conceptual Issues and Policy Questions," Journal of Urban Affairs, 28(1), 1-17.

Skarmeas, D., and C.S. Katsikeas (2001). "Drivers of Superior Importer Performance in CrossCultural Supplier- Reseller Relationships," Industrial Marketing Management, 30, 227-241.

Skarmeas, D., and J. M. Robson (2008). "Determinants of Relationship Quality in ImporterExporter Relationships," British Journal of Management, 19, 171-184.

Street, C.T., and A. Cameron. (2007). "External Relationships and the Small Business: A Review of Small Business Alliance and Network," Journal of Small Business Management, 45(2), 239-266.

Stuart, T. E., and O. Sorenson (2003). "The Geography of Opportunity: Spatial Heterogeneity in Founding Rates and the Performance of Biotechnology Firms," Research Policy, 32, 229 - 253.

Teece, D.J., G. Pisano, and A. Shuen (1997). "Dynamic Capabilities and Strategic Management," Strategic Management Journal, 18(7), 509 - 533.

Torre, A., and A. Rallet (2005). "Proximity and Localization," Regional Studies, 39(1), 47-59.

Trevino, L., R. Lengel, W. Bodensteiner, E. Gerloff, and N. Muir (1990). "The Richness Imperative and Cognitive Style: The Role of Individual Differences in Media Choice Behavior," Management Communication Quarterly, 4(2), 176-197.

Ulubasoglu, M.A., M. Akdis, and S.B. Kok (2009). "Internationalization and Alliance Formation: Evidence from Turkish SMEs,” International Small Business Journal, 27(3), 337-361.

Uzzi, B. (1997). "Social Structure and Competition in Interfirm Networks: The Paradox of Embeddedness," Administrative Science Quarterly, 42(1), 35 - 67.

van Gils, A., and P.S. Zwart (2009). "Alliance Formation Motives in SMEs: An Explorative Conjoint Analysis Study,” International Small Business Journal, 27(5), 5-37.

Verspagen, B., and G. Duysters (2004). "The Small Worlds of Strategic Technology Alliances," Technovation, 24, 563-571.

Weerawardena, J., G. S. Mort, P.W. Liesch, and G. Knight (2007). "Conceptualizing Accelerated Internationalization in the Born Global Firm: A Dynamic Capabilities Perspective," Journal of World Business, 42(3), 294 - 306.

Wiklund, J., and D.A. Shepherd (2009). "The Effectiveness of Alliances and Acquisitions: The Role of Resource Combination Activities," Entrepreneurship Theory and Practice, 33(1), 193212.

Zaheer, S., and A. Zaheer (2006). "Trust Across Borders," Journal of International Business Studies, 37(1), 21-29.

Zaheer, S., A. Lamin, and, M. Subramani (2009). "Cluster Capabilities or Ethnic Ties? Location Choice by Foreign and Domestic Entrants in the Services Offshoring Industry in India," Journal of International Business Studies, 40, 944 - 968.

Zaheer, A., B. McEvily, and V. Perrone (1998). "Does Trust Matter? Exploring the Effects of Interorganizational and Interpersonal Trust on Performance," Organization Science, 9(2), 141159. 
Figure 1. Data Structure

\section{$1^{\text {st }}$ Order Concepts}

- Establish informal, unstructured search and selection routines

- $\quad$ Prepare detailed and clear technical specifications

- Implement additional quality assurance steps for testing

- Develop project management routines

- Develop administrative capabilities

- Implement a distributed development environment

- Develop negotiation skills

- $\quad$ Design and implement strong agreements $2^{\text {nd }}$ Order Themes

Aggregate Dimensions
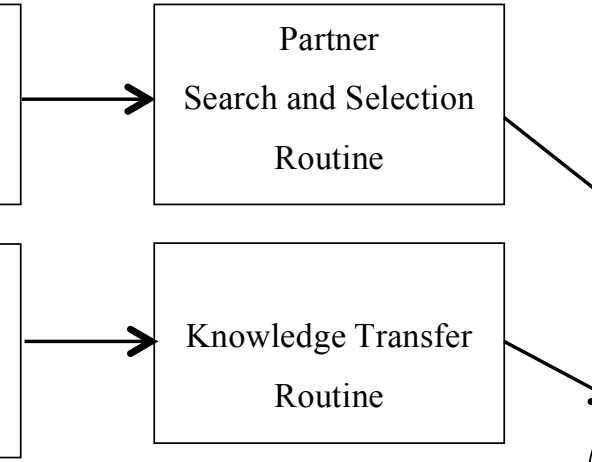

.
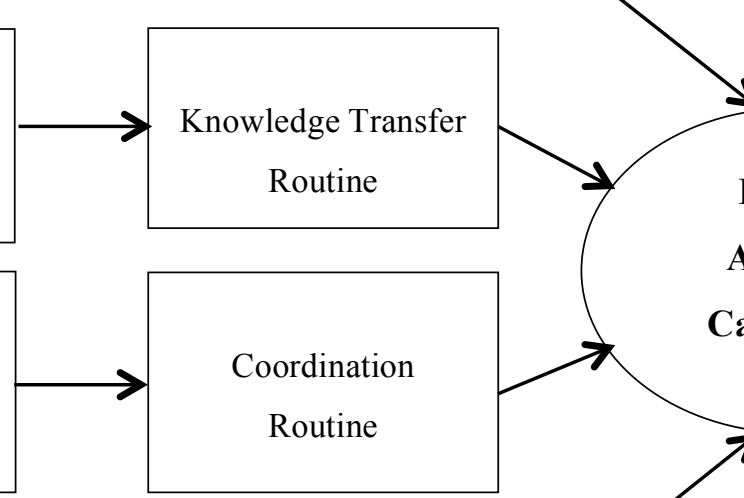

Firm's

Alliance

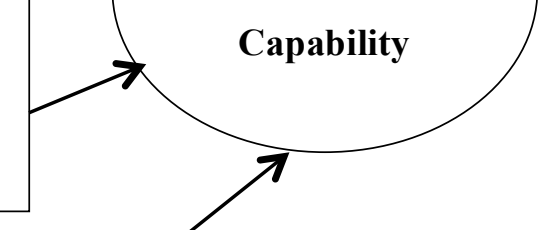

Governance

Routine

- Senior managers' networks and connections

- Technology partnership programs

- Nationwide conferences \& user groups

- Shared cultural, national or ethnical backgrounds between employees or managers of partnering firms
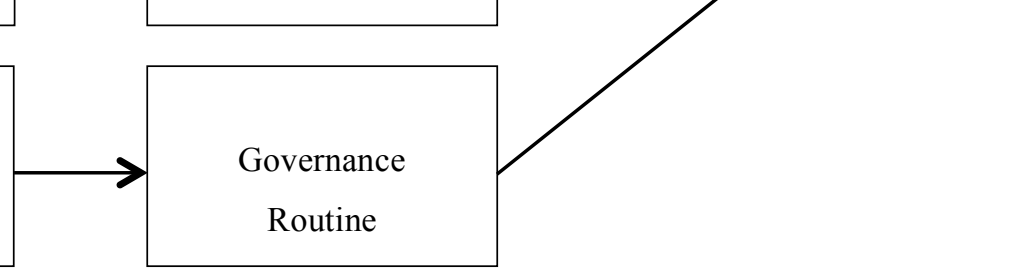
managers of part nering firms

- Existence of local marketing / sales office

- Existence of an intermediary to gather business requirements
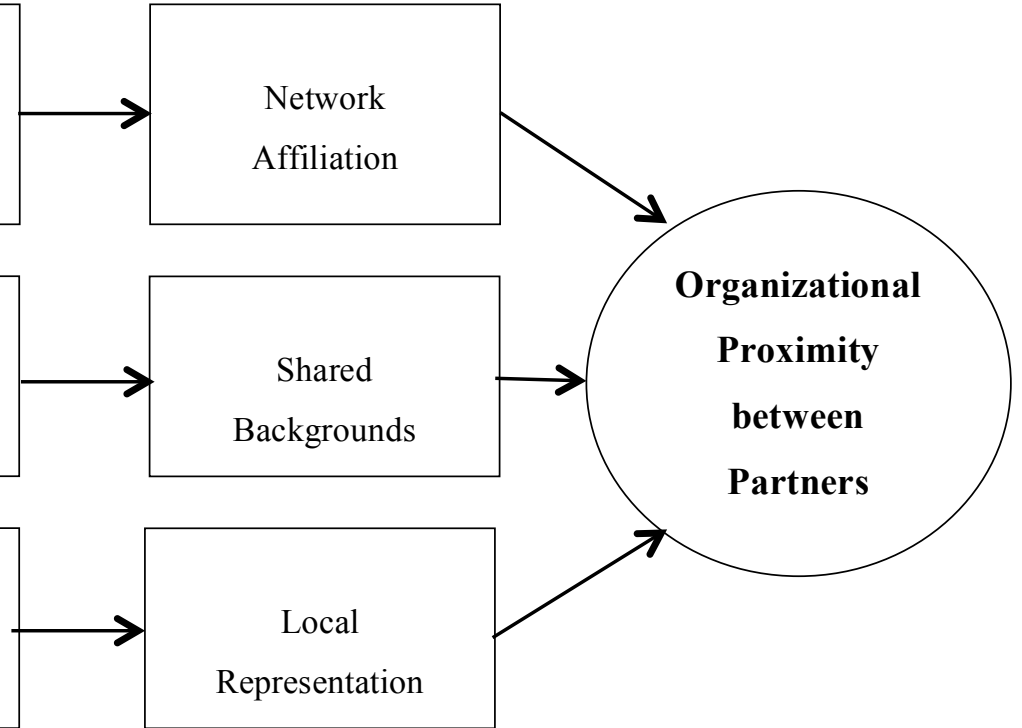

Representation

- Creative services vs. Procedural services

- Remote service provision vs. Services requiring physical presence

IT

Service

Characteristics

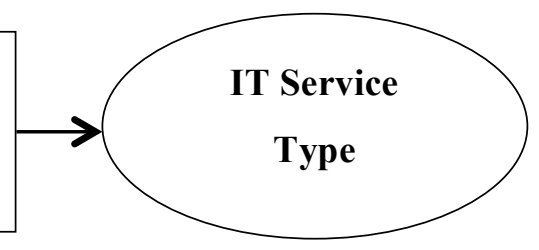


Figure 2.Proposed Research Framework

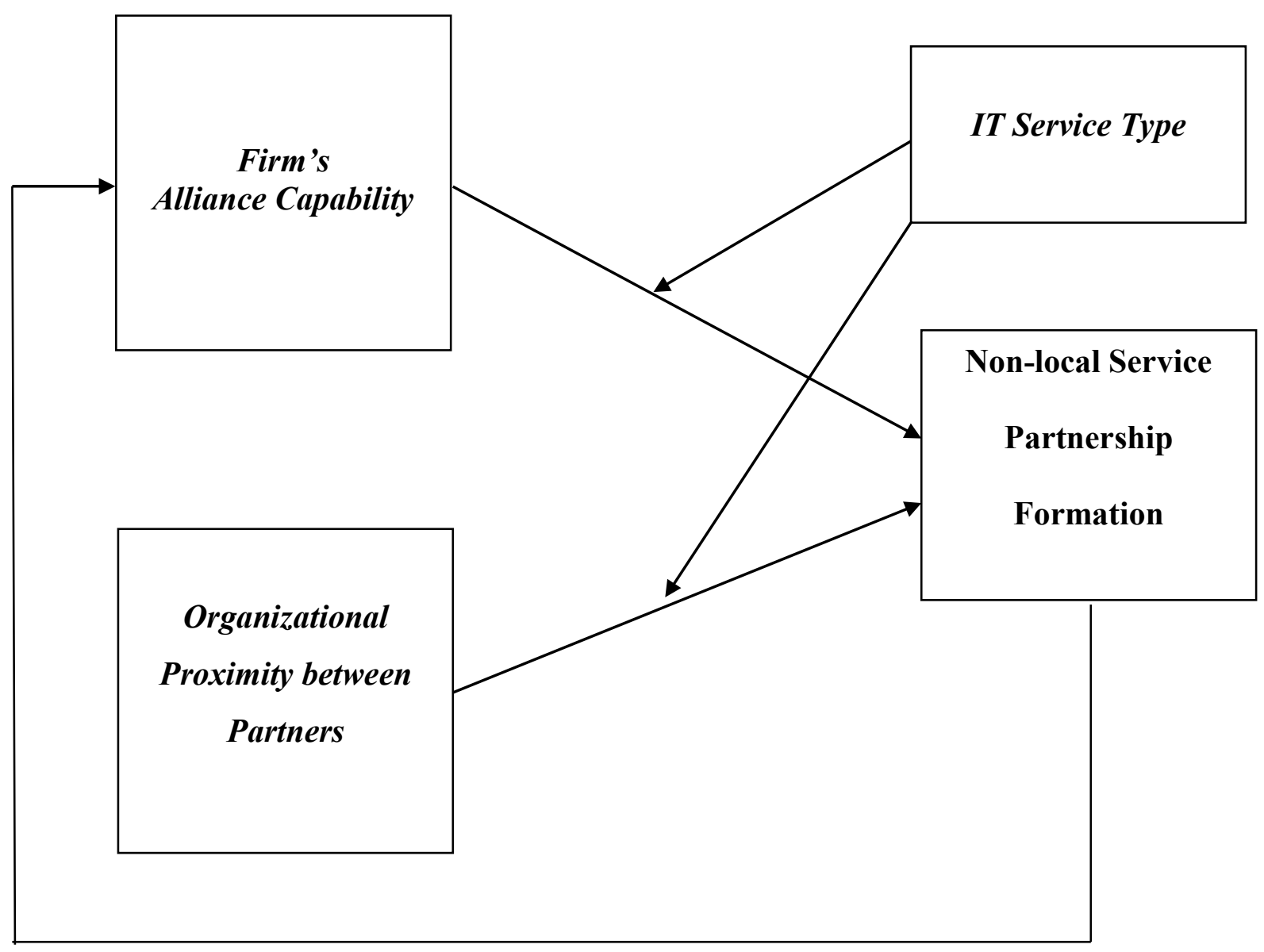


Table 1.Participants' Distribution by IT Segments

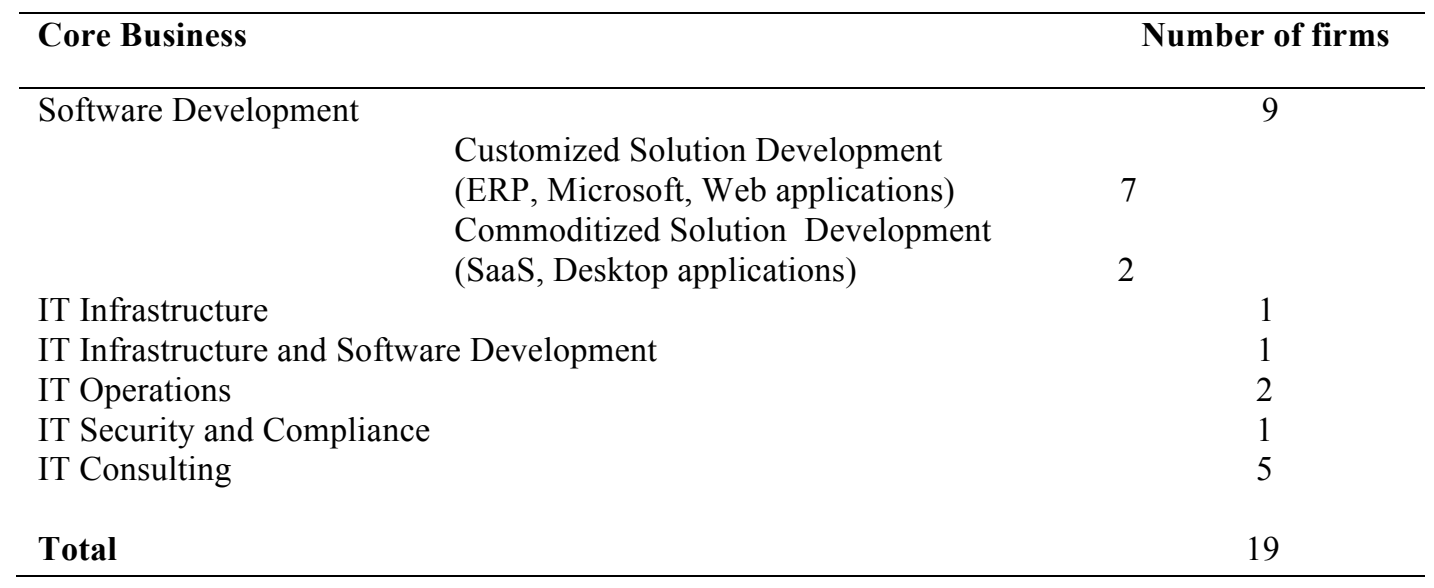

Table 2.Participants' Distribution by Partner's Location

\begin{tabular}{|c|c|c|c|c|}
\hline $\begin{array}{l}\text { Location of } \\
\text { Partner }\end{array}$ & Core Business & Firm & Size & $\begin{array}{c}\text { Specific IT Services Subject to } \\
\text { Service Partnerships }\end{array}$ \\
\hline \multirow[t]{3}{*}{ Local only } & IT Operations & Firm 9 & Micro & Telecom Svcs \\
\hline & IT Infrastructure & Firm 5 & Small & Telecom and VoIP Svcs. \\
\hline & $\begin{array}{l}\text { Customized Solution } \\
\text { Development }\end{array}$ & Firm 12 & Medium & Software Development \\
\hline \multirow{7}{*}{$\begin{array}{l}\text { Non-local } \\
\text { (Domestic) } \\
\text { Local and } \\
\text { Non-local } \\
\text { (Domestic) }\end{array}$} & IT Operations & Firm 1 & Micro & Helpdesk, Network Svcs \\
\hline & $\begin{array}{l}\text { IT Security and } \\
\text { Compliance }\end{array}$ & Firm 13 & Micro & $\begin{array}{l}\text { Local and Domestic: Security and } \\
\text { Consulting Svcs }\end{array}$ \\
\hline & IT Consulting & Firm 19 & Micro & Local and Domestic: Consulting Svcs \\
\hline & IT Consulting & Firm 14 & Small & $\begin{array}{l}\text { Local and Domestic: Software } \\
\text { Development, Consulting Svcs } \\
\text { Local: Software Development }\end{array}$ \\
\hline & IT Consulting & Firm 17 & Small & Domestic: Software Development \\
\hline & $\begin{array}{l}\text { Customized Solution } \\
\text { Development }\end{array}$ & Firm 2 & Small & $\begin{array}{l}\text { Local : Network Svcs } \\
\text { Domestic: Software Development }\end{array}$ \\
\hline & $\begin{array}{l}\text { Customized Solution } \\
\text { Development }\end{array}$ & Firm 3 & Small & $\begin{array}{l}\text { Local: User Design } \\
\text { Domestic: Hosting Svcs }\end{array}$ \\
\hline \multirow[t]{3}{*}{$\begin{array}{l}\text { Local and } \\
\text { Non-local } \\
\text { (International) }\end{array}$} & $\begin{array}{l}\text { IT Infrastructure and } \\
\text { Software } \\
\text { Development }\end{array}$ & Firm 11 & Small & $\begin{array}{l}\text { Local : Security, Telecom Svcs } \\
\text { International : Software } \\
\text { Development }\end{array}$ \\
\hline & $\begin{array}{l}\text { Customized Solution } \\
\text { Development }\end{array}$ & Firm 6 & Medium & $\begin{array}{l}\text { Local and International: Software } \\
\text { Development }\end{array}$ \\
\hline & $\begin{array}{l}\text { Customized Solution } \\
\text { Development }\end{array}$ & Firm 7 & Medium & $\begin{array}{l}\text { Local and International: Software } \\
\text { Development }\end{array}$ \\
\hline $\begin{array}{l}\text { Local and } \\
\text { Non-local } \\
\text { (Domestic \& } \\
\text { International) }\end{array}$ & $\begin{array}{l}\text { Customized Solution } \\
\text { Development }\end{array}$ & Firm 10 & Medium & $\begin{array}{l}\text { Local : Network Svcs, User Design } \\
\text { Domestic: Hosting Svcs } \\
\text { International: Software Development }\end{array}$ \\
\hline
\end{tabular}




\section{Table 3.Non-local Partnership Challenges}

\begin{tabular}{|c|c|c|}
\hline $\begin{array}{l}\text { Partnership } \\
\text { Activity }\end{array}$ & $\begin{array}{c}\text { Partnership } \\
\text { Challenge }\end{array}$ & Sample Quote \\
\hline Partner Search & $\begin{array}{l}\text { Lack of resources for } \\
\text { search and selection in } \\
\text { non-local markets }\end{array}$ & $\begin{array}{l}\text { But smaller companies don't really have all the time to try to } \\
\text { understand and research companies that they don't know } \\
\text { especially [non-local service providers] trying to service from } \\
\text { [abroad] into Chicago. Participant } 12\end{array}$ \\
\hline Communication & $\begin{array}{l}\text { Time zone differences } \\
\text { Availability issues } \\
\text { Lack of FTF contact with } \\
\text { the non-local partner }\end{array}$ & $\begin{array}{l}\text { I would say communication, time zones and availability would } \\
\text { be the three big disadvantages. Participant } 6 \\
\text { All your interaction is via e-mail or phone. We are very } \\
\text { relationship oriented company. And it is a disadvantage not to } \\
\text { have the face to face. They were having a meeting Friday } \\
\text { morning at ten o'clock. We'd like to be there as supposed to } \\
\text { "let's do a conference call". So, that's how we'd say non-local } \\
\text { firms have a disadvantage. Participant } 6\end{array}$ \\
\hline $\begin{array}{l}\text { Knowledge } \\
\text { Transfer }\end{array}$ & $\begin{array}{l}\text { Difficulty in sharing } \\
\text { customer requirements } \\
\text { over distance }\end{array}$ & $\begin{array}{l}\text { When I am trying to give them an understanding of the project of } \\
\text { what we are looking for, it takes a lot of time on my end to } \\
\text { explain to them what exactly I want. Participant } 2 \\
\text { So let's say a company needs software for their shop floor area in } \\
\text { a manufacturing plant and it is helping them with new products } \\
\text { and it's related to the equipment laid out on their plant floor. } \\
\text { How to deal with the discussions remotely? So that people try to } \\
\text { visualize and crystallize what the customer is asking makes it } \\
\text { extremely tough. Participant } \mathbf{1 2}\end{array}$ \\
\hline Coordination & $\begin{array}{l}\text { Project and quality } \\
\text { management problems }\end{array}$ & $\begin{array}{l}\text { We can't just send them a project and expect that it is going to } \\
\text { come back perfect. You know there is, you have to do a lot of } \\
\text { Q\&A work, and just have to be a lot more specific about what } \\
\text { you tell them to do. Participant } 11\end{array}$ \\
\hline Governance & $\begin{array}{l}\text { Customer ownership and } \\
\text { channel conflict }\end{array}$ & $\begin{array}{l}\text { It's a very complicated relationship because we are competitors } \\
\text { in a sense, because they have direct sales force in US, trying to } \\
\text { find the kind of work that we are trying to find. So there is } \\
\text { potential for channel conflict. Participant } 7\end{array}$ \\
\hline
\end{tabular}


Table 4.Firms' Routines to Overcome Non-local Partnership Challenges

\begin{tabular}{|c|c|c|}
\hline $\begin{array}{l}\text { Partnership } \\
\text { Activity }\end{array}$ & Organizational Routine & Sample Quote \\
\hline Partner Search & $\begin{array}{l}\text { Establish informal, } \\
\text { unstructured search and } \\
\text { selection routines }\end{array}$ & $\begin{array}{l}\text { We did evaluate at the location in India, try to find a location that } \\
\text { has a lower turnover rate of employees. We needed to meet } \\
\text { people and see and have them actually prove themselves and } \\
\text { build and earn trust that they are a company we can count on. } \\
\text { Participant } 10 \\
\text { We went through partner selection process, we elected the size of } \\
\text { the company, what skills they have and what the reputation was, } \\
\text { what they can offer us. Participant } 7\end{array}$ \\
\hline $\begin{array}{l}\text { Knowledge } \\
\text { Transfer }\end{array}$ & $\begin{array}{l}\text { Prepare detailed and clear } \\
\text { specifications } \\
\text { Implement additional } \\
\text { quality assurance steps }\end{array}$ & $\begin{array}{l}\text { But if I give you a booklet, a specific booklet when everything is } \\
\text { laid out and "this is what we want you to develop", that's work } \\
\text { well. Because you can source it at lowest possible cost to } \\
\text { complete the setting is defined. It is defined to } 100 \% \text { completion. } \\
\text { Participant } 12 \\
\text { So, here with our team of developers, I can just say "here is a } \\
\text { project, go ahead and do what you are told". [ ] I have to very } \\
\text { much have it spec'ed out, very specific, and that when they send } \\
\text { back the code has to be Q\&A'd by somebody from our side. } \\
\text { Participant } 11\end{array}$ \\
\hline Coordination & $\begin{array}{l}\text { Develop project } \\
\text { management skills } \\
\text { Develop administrative } \\
\text { capabilities } \\
\text { Implement a distributed } \\
\text { development environment }\end{array}$ & $\begin{array}{l}\text { I mean, our strength is we have a lot of project management type } \\
\text { of experience. We are capable of handling a project of higher end } \\
\text { and dishing out the work to [non-local firm]. Participant } 2 \\
\text { Larger companies which have more bandwidth or in terms of } \\
\text { internal administrative capabilities and also can accept more of a } \\
\text { distributed development environment, they are much more easier } \\
\text { to make that kind of moves. Participant } 12\end{array}$ \\
\hline Governance & 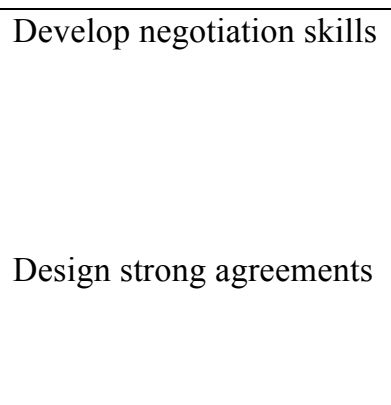 & $\begin{array}{l}\text { It's a very complicated relationship because we are competitors } \\
\text { in a sense. [ ] And it was a long term deal with a lot of money, so } \\
\text { we negotiated the settlement whereby [firm] gets basically } \\
\text { commission. Participant } 7 \\
\text { We have a non- compete where they are not allowed to write any } \\
\text { contracts directly and any work needs to be done has to be done } \\
\text { through [firm]. Participant } 10\end{array}$ \\
\hline
\end{tabular}




\section{Appendix A: Interview Protocol}

\section{Firm demographics}

a. What is the size of your firm i.e. number of total employees and IT workforce?

b. When was your firm established?

c. For how long has your firm been in Chicago? And why?

2. Services and products offered

a. What kind of IT services does your firm provide? [Follow up examples: software /application/ platform or services]

b. What is your firm's competitive advantage in the market? [Follow up examples: cost - price, differentiation, quality, product innovation, time to market]

3. Customer information

a. What is your firm's target customer market? [Follow up: customers' industry and size]

b. Where does your firm operate mainly i.e. inside of Chicago, outside Chicago in US, or outside of US?

4. Partnership definition

a. How do you describe partnerships in your business?

b. What is the role of partnerships in your business and IT industry in general?

c. What type of partnerships do you have with other IT firms?

5. Impact of partnerships on competitive advantage

a. What is the impact of your partnership strategy on your firm's competitive advantage? [Follow up examples: cost - price, differentiation, quality, product innovation, time to market]

b. How do you avoid direct competition in your partnerships?

6. Sourcing strategy - partnership perspective [Not included in the analysis]

a. How does your firm source internal IT activities, what services are in-sourced and out-sourced? Why do you choose so? 
b. If you outsource any internal IT activity, how do you choose partners? Are there any criteria to select partners? And why?

c. If applicable, please describe existing partnerships in terms of partners (size, subsector, and capabilities), customer, and IT service provided.

- Are the partners located in Chicago, outside Chicago or outside US? Do you have any locational preference for this partnership? Why?

- Are these long term and strategic partnerships? Or short-term partnerships? Why?

- What are the benefits/ challenges of these local or non-local partnerships?

7. Service provision strategy - partnership perspective

a. How does your firm provide IT services to the market i.e. directly by your firm or jointly with other IT firms? Do you subcontract?

b. Do you partner up with other IT firms? If so, what is the rationale behind, under what conditions? If not, why so?

c. What services are offered directly, what services are offered jointly? Why do you choose so?

d. If you cooperate with other IT firms, how do you choose partners? Are there any criteria to select partners? And why?

e. If applicable, please describe existing partnerships in terms of partners (size, subsector, and capabilities), customer, and IT service provided.

-Are the partners located in Chicago, outside Chicago or outside US? Do you have any locational preference for this partnership? Why?

- Do customer preferences impact your partnership choices especially in terms of location? If so, to what extent?

- Are these long term and strategic partnerships? Or short-term partnerships? Why?

- What are the benefits/ challenges of these local or non-local partnerships?

8. Experience with distant / non-local partnerships. 
a. [If not stated before] Have you ever considered engaging into distant partnerships (out of region, global)? Why or why not?

b. What do you consider as advantages or disadvantages of distant relationships?

c. What do you think is your firm's strengths or weaknesses for setting and maintaining distant relationships?

9. Other partnerships

a. Do you have partnerships with other type of firms (e.g. customers, other services firms, universities, research institutions, universities, public offices)? If so, what is the purpose of this cooperation?

\section{Chicago [Not included in the analysis]}

a. What aspects of Chicago are important for your firm's being located here?

b. Considering your business model, can you think of any advantages or disadvantages of being located in Chicago?

[Follow up examples: infrastructure \& transportation / availability of specialized labor/ proximity to customers/ existence of other services companies/ government support / existence of IT community, associations, networks, research and educational institutions]

\section{Impact of economic crisis [Not included in the analysis]}

a. How do you think has the current economic crisis influenced your partnership strategy?

Thank you for your time and contribution. 